\title{
Editorial
}

\section{The way ahead}

\author{
World Rheumatism Year and after
}

Our Editorial at the beginning of this volume focused on international rheumatology in World Rheumatism Year (WRY). Now, almost a year later, it is appropriate to take stock. Some changes are obvious - hair a little thinner or greyer, faces a little more lined, posture rather less upright, and gait not so springy. But the aging of connective and other tissues is inexorable. Nevertheless, a great deal of effort has been applied to WRY, and we must consider what has been accomplished.

Although many people feel the Post Office is getting ever more behindhand with the mails, it is ahead with some things -15 years or so ahead of the average for the country as a whole in time lost from work due to sickness, for instance. Rheumatic complaints play a large part in this incapacity but, to their shame and ours, the British Post Office declined to issue special stamps for WRY. Not so in Belgium, Bulgaria, DDR, Greece, Poland, and Thailand, nor in Kuwait and Lesotho-the two latter not notable previously for their commitment to rheumatology, but all the more welcome for that.

The World Health Organization gave official endorsement to WRY, and it expressed its support in constructive form by devoting the June issue of World Health to rheumatism. Published in Arabic, English, French, German, Persian, Portuguese, Russian, and Spanish, this was the widest simultaneous language coverage for any WRY material. Many national journals in other countries produced special WRY issues, though some of our own general medical journals found themselves unable to lend their support to disseminating rheumatological knowledge in this way. However, other publications have been more helpful, and a recent special WRY issue of Modern Medicine was particularly welcome, not least by featuring the newly-emerging generation of rheumatologists as contributors.

1977 has been disappointing in other respects. First, it was the year the Greater Glasgow Health

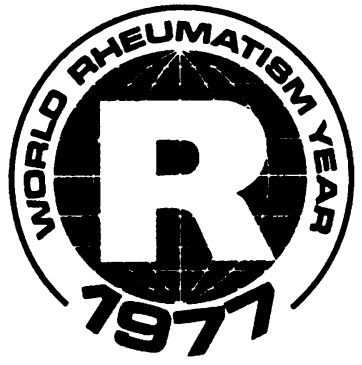

Board sought economies by trying to close the Centre for Rheumatic Diseases in Baird Street for a couple of weeks. It is a brave man who takes on Goliath, especially when he wears a kilt, and on this occasion the sling was a poor match for public outcry and rhetoric in Parliament, ably organized by Watson Buchanan and his associates. Second, the prospect for professorial chairs has not been encouraging. Bristol had an able candidate but the opportunity was lost-Malcolm Jayson has moved to Manchester, succeeding to J. H. Kellgren's position. North of the border there is also uncertainty about the future, with the retirement of J. J. R. Duthie. Third, rheumatologists have had to fight hard to protect facilities, and this despite the fact that 23 area health authorities in England and Wales are without the benefit of consultant advice.

But the tale is by no means one of unrelieved gloom, and considerable credit is due to the many thousands who have made a contribution. Evaluation is concerned with examining the extent to which objectives have been attained. It is therefore necessary to refresh memories of the objectives identified by the International League against Rheumatism (ILAR). These were:

- to promote increased knowledge, understanding, and concern for the nature and scope of rheumatic diseases;

-to stimulate improvement in the availability and quality of all levels of intervention and care offered to rheumatic sufferers;

- to strive for the action and research necessary for changes to be made in understanding and care.

With the patronage of HRH The Duke of Edinburgh, plans for 1977 were developed by the British League against Rheumatism (BLAR), under the inspired leadership of the late Michael Mason. Most British rheumatologists have taken the 
initiative locally, in co-operation with the Arthritis and Rheumatism Council, the British Rheumatism and Arthritis Association, and various pharmaceutical companies. As a result there has been a nationwide series of symposia concerned with continuing education, particularly directed at general practitioners and other health professionals.

The background to these activities has been a sequence of press conferences relating to specially prepared reports. The latter, derived largely from evidence submitted to the Royal Commission on the National Health Service, focused attention in turn on the nature of rheumatic suffering, deficiencies in primary care and in the availability of specialist services, the potential of surgical joint replacement, neglect in the provision of social and welfare services, and current research activities. The response by the media has been very encouraging, and arthritis and rheumatism are now better understood and to the forefront of people's minds. Space precludes fuller mention of the divers other ways in which imagination and commitment have been harnessed to WRY.

In the meantime, economic difficulties have affected seriously the Health Service. However, as a result of the activities of BLAR, a delegation of rheumatologists held discussions with the senior minister, the Secertary of State for Health and Social Services. Concerned to explore how perpetuation of previous neglect could be avoided, despite the unfavourable financial climate, the dialogue is continuing. Central guidance has limited impact, unless it is incorporated into policy at regional and local levels. Unfortunately the mechanism for ensuring standards regionally has generally been weak, but efforts to improve the situation have been another yield from WRY.

In a situation of difficulty it is common for individuals to offer a variety of solutions off the cuff. Frequently, though, the need is more for a thorough appraisal of the problem, and satisfactory remedies can rarely be prescribed until this has been carried out. Perhaps the greatest result from WRY has been the development of a more complete appraisal of the problems. Demand, resources, and standards are inextricably linked. Rheumatology's access to resources lies through government disbursements for health service facilities and for research, and through the generosity of voluntary contributors. The need for sustained support and expanded resources has been clearly made, and thete are signs that demand is becoming more articulat产, and more effective.

What has emerged has been the shortcomings standards. Thus World Rheumatism Year has beep of immense value more by diagnosing the proble with greater precision, and by stimulating demand for change, than by finite accomplishments. Rather than being a one-off event, WRY has established a secure foundation on which we must now build We can look to the future with optimism providing we assimilate the lessons and act on them.

One aspect of standards has already beêे mentioned, namely regional guidance on local needs. More fundamental, though, is the genera challenge of education. Recognizing this, BLA intends to make 1978 a year devoted to education, a fitting sequel to WRY. A further series of reports is planned, and working parties are active in the preparation of these. What is emerging is that problem of education has been underestimates. There is still no uniformity in undergraduage training, and so a national policy is being sought. Much could be done to improve vocational âng continuing education, and to this end dialoguegas been initiated with orthopaedic surgeons saind general practitioners through their professiơnil bodies. Other health professionals are often the point of first contact-for instance, many peopde consult a pharmacist when they first experien musculoskeletal pain-and so far little attention has been paid to the enlightenment of these col leagues. Finally, health education about rheumatie disorders is often sought, but so far has receiv scant attention other than what has resulted as by-product from attempts to seek publicity. Te Arthritis and Rheumatism Council handbooks, after all, are directed at patients rather than public.

This Editorial has deliberately included reminders of our vulnerability, to emphasize that all of need to play a part. The skills of the consultant ase precious and can never be made available to evergone. The only way to extend the benefit of this expertise is by increased investment in education, and the contributions of all will be required make this effort successful. 1977 has been the yest during which we have learned; 1978 will be the year during which we shall help others to learn. 